\title{
Penetrógrafo eletrônico automático ${ }^{1}$
}

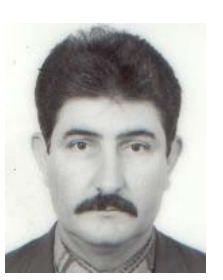

\author{
Aloísio Bianchini ${ }^{2}$, João C. de S. Maia ${ }^{3}$, Paulo S. G. Magalhães ${ }^{4}$, Nelson Cappelli ${ }^{4}$ \& Cláudio K. Umezu ${ }^{5}$ \\ 1 Trabalho financiado pela Fundação de Amparo à Pesquisa do Estado de Mato Grosso - FAPEMAT \\ 2 Dept. Solos e Eng. Rural - FAMEV/UFMT. E-mail: bianchi@cpd.ufmt.br (Foto) \\ ${ }^{3}$ Dept. Solos e Eng. Rural - FAMEV/UFMT \\ ${ }^{4}$ Faculdade de Eng. Agrícola - UNICAMP \\ ${ }^{5}$ Universidade São Francisco - USF
}

Protocolo 090 - 19/6/2001

\begin{abstract}
Resumo: O presente trabalho relata o desenvolvimento de um penetrógrafo, construído para operar de forma automática, executando um ensaio de penetração com um simples toque no botão de partida. Ele possui incorporado, um sistema dedicado de aquisição de dados, que pode armazenar até 187 ensaios e uma interface de comunicação, dispensando a conexão ao microcomputador ou "datalogger". As condições do ensaio como, por exemplo, data, localização (latitude e longitude) e profundidade, podem ser atualizadas, assim como a aferição da célula de carga, via teclado com mostrador de duas linhas. Verificou-se variação de velocidade $\leq 5 \% \mathrm{com}$ relação à do padrão $A S A E$, para índices de cone entre 500 e $5.684 \mathrm{kPa}$. O equipamento é compacto, de fácil manuseio e com capacidade operacional de até um ensaio por minuto.
\end{abstract}

Palavras-chave: índice de cone, compactação de solo, agricultura de precisão

\section{Automatic electronic recording penetrometer}

\begin{abstract}
This paper presents the development of an automatic recording penetrometer, which operates at the touch of a button. It incorporates a data acquisition system, which can store data of 187 tests and has a serial PC interface. The test characterization such as dates, location (latitude and longitude) can be recorded as well. The maximum working depth may be set and the load cell calibration can be verified through a keyboard with 2 lines display. A speed variation error of $\leq 5 \%$ compared to ASAE standard was verified for cone indices between 500 and $5,684 \mathrm{kPa}$. The equipment is compact, easy to handle and can realize one test every minute.
\end{abstract}

Key words: cone index, soil compaction, precision agriculture

\section{INTRODUÇÃO}

A automação da coleta de dados de resistência do solo à penetração, é a opção mais adequada para o levantamento da compactação de solos, no âmbito da agricultura de precisão; no entanto, penetrógrafos automáticos com sistema dedicado de aquisição de dados não estão disponíveis no mercado nacional, sendo necessário desenvolvimento experimental para que um modelo comercial possa ser apresentado. Este tipo de equipamento apresentaria, em relação aos de operação manual, maior capacidade e menor custo operacional, além de fornecer informações mais confiáveis, em função de um controle melhor da velocidade do cone.

De acordo com Mantovani et al. (1998) nota-se intensa modificação do meio rural nos Estados Unidos e na Europa, que agora também se inicia no Brasil. Esta modificação se deve ao uso intensivo de tecnologia de ponta, voltada para aumentar a capacidade de trabalho da propriedade e a precisão dos equipamentos, visando à racionalização do uso dos recursos naturais e redução do efeito nocivo ao meio ambiente. Este trabalho tem sido possível, conforme os autores, graças ao uso de automação, instrumentação e ferramentas de suporte à tomada de decisão.

Esta nova visão de agricultura, denominada agricultura de precisão, depende de um número expressivo de informações, principalmente a respeito do clima, das propriedades rurais $\mathrm{e}$ das características dos solos, bem como da ocorrência de ervas daninhas, pragas e doenças, uma vez que cada informação deve representar a menor área possível. Para Sudduth (1998) em campos que estão sendo mapeados pela primeira vez, o espaçamento da malha amostral deve ser pequeno, para que se possa representar corretamente a variabilidade existente. Espaçamentos entre 20 e $30 \mathrm{~m}$ têm sido utilizados em áreas experimentais, enquanto nas áreas comerciais o número de amostras coletadas tem sido bem inferior, da ordem de 1 a 2,5 para cada hectare. 
O custo é o fator limitante para a utilização de malhas com pequeno espaçamento entre amostras. Ferramentas como a geoestatística, têm-se mostrado valiosas para ciência do solo na caracterização e mapeamento da variação espacial de suas características e propriedades (Webster \& Oliver, 1990). Por outro lado, o desenvolvimento de equipamentos e transdutores que visam reduzir o tempo amostral e os custos da amostragem e da análise, tem-se apresentado muito promissor, principalmente em se considerando a enorme contribuição que a eletrônica vem oferecendo para o setor.

De acordo com Perumpral (1987) os penetrômetros vêm sendo empregados em grande escala no meio agrícola, para diversas aplicações, por serem de utilização fácil, rápida e barata, com fácil interpretação dos resultados, principalmente para a determinação da resistência do solo à penetração de raízes e detecção de camadas de solo compactadas. A bibliografia cita, com freqüência, os penetrógrafos eletrônicos manuais, com transdutores para a aquisição de dados de força e deslocamento da haste de penetração, evidenciando suas vantagens (Cappelli et al., 1995 e Moreira et al., 1995, entre outros). No entanto, esses equipamentos são acionados manualmente, podendo causar imprecisões de leitura, como alertam Camargo \& Alleone (1997). Algumas fontes de erros consideráveis na determinação do índice de cone, por meio de penetrógrafos manuais, estão relacionadas à impossibilidade de se manter uma velocidade constante durante o tempo de penetração da haste e pela incerteza de se operar o equipamento a uma velocidade de penetração próxima à normalizada.

Williford et al. (1972) construíram um penetrógrafo hidráulico, montado em trator agrícola, para levantamento de campo. Na época, os dados coletados de força e deslocamento eram enviados para um registrador X-Y. Os autores, após 2 anos de trabalho em campo, concluíram que o tempo de aquisição dos dados de índice de cone foi de $1 / 4$ do tempo utilizado por penetrógrafos manuais.

Mais recentemente, Santos \& Lanças (1999) desenvolveram um penetrógrafo hidráulico- eletrônico, que usa como fonte de potência a tomada do controle remoto do trator agrícola. Neste projeto, o sistema de aquisição de dados estava pautado em um data-logger "MicroLogger 21 X" e acessórios, para receber as informações da célula de carga e do potenciômetro. Os autores constataram, ainda, diferenças significativas entre os dados obtidos pelo penetrógrafo manual e pelo hidráulico, atribuindo essas diferenças ao melhor controle de velocidade obtido no penetrógrafo hidráulico.

Lins e Silva (1999) realizaram estudos em laboratório, utilizando-se de um penetrógrafo hidráulico que permitia a regulagem da velocidade de penetração do cone. Os ensaios foram conduzidos com velocidades de penetração entre 5 e $100 \mathrm{~mm} \mathrm{~s}^{-1}$. Os resultados por eles obtidos demonstraram uma tendência crescente e significativa do índice de cone, com o aumento da velocidade de penetração, quando se mantiveram constantes a umidade e a densidade, em todas as colunas de solo ensaiadas.

O presente trabalho tem por objetivo apresentar um penetrógrafo eletrônico automático, compacto, projetado e construído de modo que seu manuseio fosse fácil e o custo operacional baixo, que tem um sistema de aquisição de dados dedicado e que pode ser acoplado ao trator agrícola.

\section{MATERIAL E MÉTODOS}

O penetrógrafo foi construído de acordo com a norma S313-2 (ASAE, 1998). A sua concepção foi pautada na idéia de que ele deveria funcionar automaticamente, tendo sua própria fonte de potência e sistema de aquisição de dados, além de ser um equipamento robusto, compacto, de fácil manuseio e baixo custo operacional. Elegeu-se, desta forma, o parafuso de potência acoplado a um motor elétrico e sistema de transmissão para deslocamento da haste com o cone. O dimensionamento das peças do penetrógrafo foi feito considerando-se que elas deveriam suportar, com segurança, uma força de compressão na haste de penetração de até $1500 \mathrm{~N}$.

Após a usinagem das peças construtivas, o penetrógrafo foi montado em laboratório e ajustado para que houvesse um perfeito funcionamento entre as partes mecânicas; em seguida, calibrou-se a célula de carga, para que o sinal analógico por ela emitido pudesse ser convertido em valores da grandeza-força. Foram realizados testes em laboratório, com cargas constantes para verificação da integridade da estrutura e a variação da velocidade de deslocamento do cabeçote, que conduz a haste com o cone de penetração.

O sistema de controle e aquisição de dados foi projetado utilizando-se de um microcontrolador, com a função de controlar todas as operações realizadas pelo sistema (aquisição e gravação de dados, automação do equipamento, leitura do teclado, controle do display e transferência de dados). Além do microcontrolador utilizou-se, também, um conversor analógicodigital (A/D) de 12 bits, com a função de converter o sinal analógico advindo da célula de carga em sinal digital. A alimentação e a amplificação do sinal foram feitas por meio de um circuito integrado com fonte de tensão precisa e ganho programável.

\section{Descrição do equipamento}

O princípio de funcionamento do penetrógrafo consiste na utilização de dois parafusos de potência, com 1,00 m de comprimento, que se encarregam de deslocar um cabeçote ao qual está presa a haste do cone. Entre o cabeçote e a haste foi colocada uma célula de carga tipo S, com capacidade de $2.000 \mathrm{~N}$ (a célula apresentou, na calibração, um erro total combinado para compressão de $0,14 \%$ ). Como fonte de potência foi utilizado um motor de $12 \mathrm{Vcc}, 300 \mathrm{~W}$ a 3.000 rotações $\mathrm{min}^{-1}$.

Um sistema de transmissão tipo parafuso sem-fim, foi colocado entre o motor e os parafusos de potência, com a finalidade de reduzir a rotação e permitir o deslocamento do cabeçote a uma velocidade de $30 \mathrm{~mm} \mathrm{~s}^{-1}$. No sistema de transmissão colocou-se um transdutor indutivo modelo SL-22 G1 1PA, que emite um pulso a cada 2,5 $\mathrm{mm}$ do deslocamento do cone de penetração.

\section{RESULTADOS E DISCUSSÃO}

Foi montado no cabeçote um transdutor capacitivo, modelo SC-200/CA, cuja finalidade é avisar ao sistema de controle e aquisição de dados, o momento em que a base do cone se encontra rente ao solo e que deve ser iniciada a coleta de dados. Também existe um transdutor magnético tipo "reed swich", que 
tem a função de avisar ao sistema a posição em que o cabeçote deve parar quando a haste está sendo retirada do solo.

A Figura 1 mostra o penetrógrafo após a conclusão da instalação do sistema de aquisição de dados na parte mecânica. Pode-se observar que o equipamento é compacto, robusto e de tamanho reduzido, consonante os propósitos do projeto inicial.

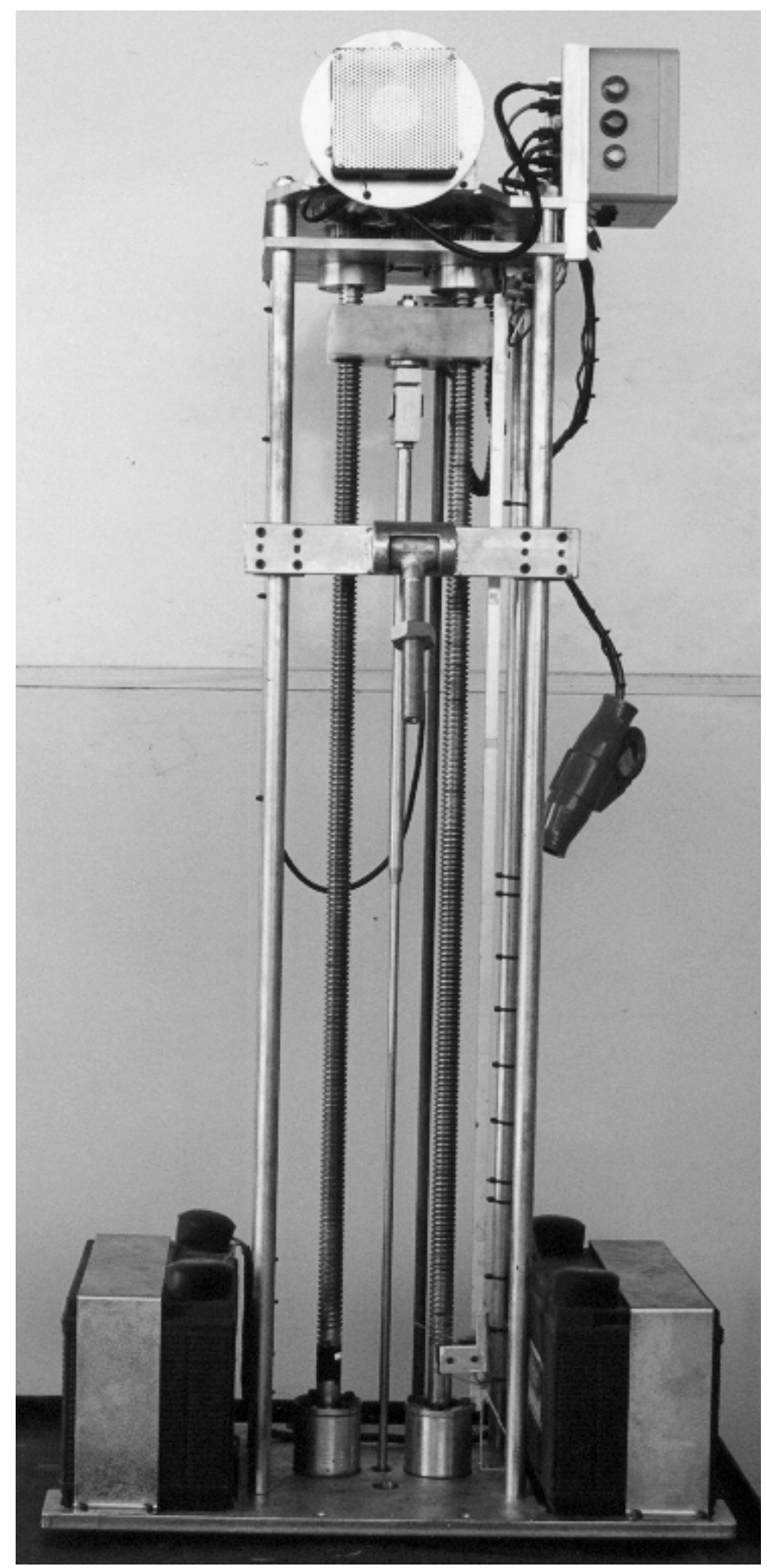

Figura 1. Vista geral do penetrógrafo eletrônico automático

A placa de aquisição de dados foi desenvolvida especialmente para utilização no penetrógrafo, tendo como principal componente um microcontrolador modelo 16F877, da família 16F87X, da Microchip Techenology Inc. Este microcontrolador tem processamento em 8 bytes, arquitetura RISC (Reduced Intructions Set Computer), 8 kbytes de memória tipo Flash para armazenamento de programas, 256 bytes de Memória RAM para armazenamento de dados, e interface para programação via padrão RS-485.

A Figura 2 mostra o equipamento montado em um trator pronto para operação em campo. Observa-se que ele é montado sobre a barra de tração, dispensando qualquer tipo de adaptação ou acessório instalado no trator.

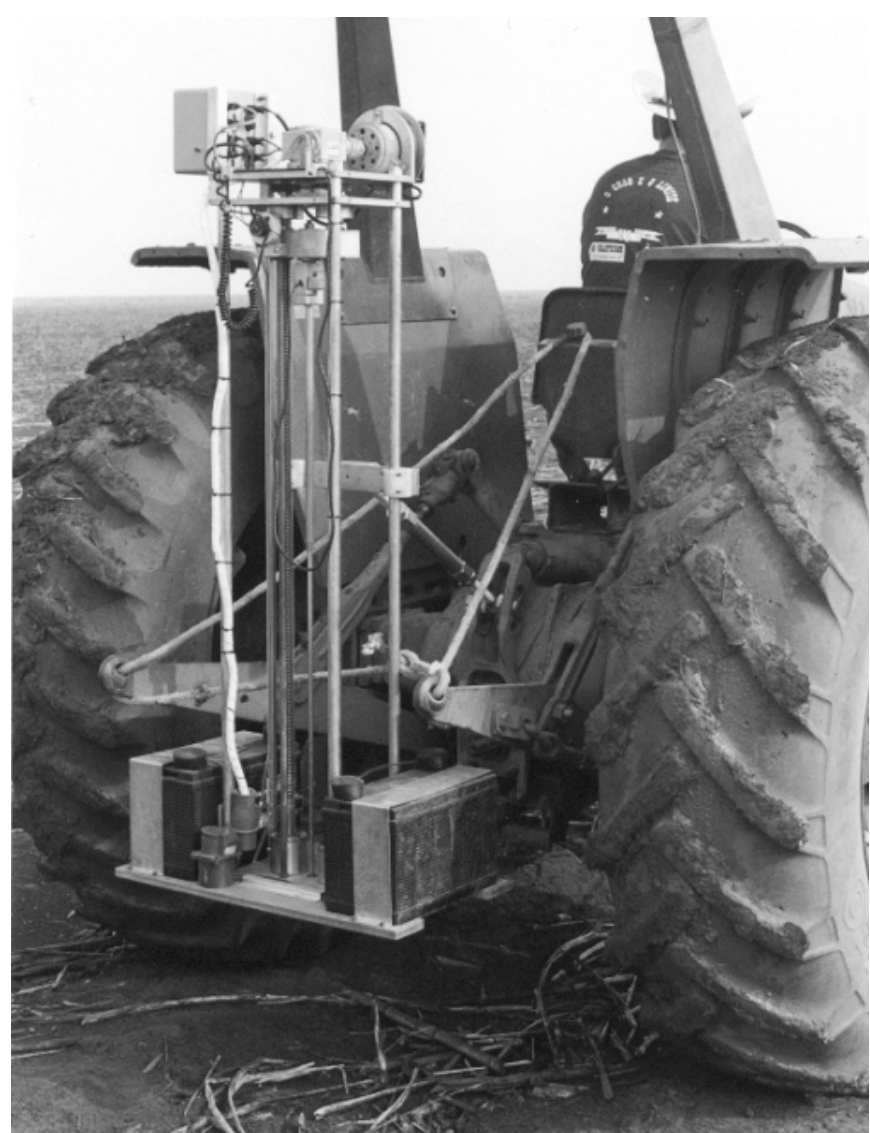

Figura 2. Penetrógrafo eletrônico montado no trator

A placa controla, também, 2 relés de 12 Vcc - 35 Amperes, utilizados para a automação do movimento da haste e, por meio dos relés, ela aciona e inverte a rotação do motor, de forma que seja possível a introdução da haste do cone no solo, até a profundidade programada e o seu recolhimento, à posição original de forma automática.

Para a leitura do sinal correspondente à força de penetração, utilizou-se um conversor analógico-digital (A/D) de 12 bits, modelo ADS7824, fabricado pela Burr-Brown Corp, com tecnologia CMOS e 4 canais analógicos de entrada.

O banco de memória tem a função de armazenar os resultados das medições realizadas com o equipamento e é constituída, fisicamente, por 4 dispositivos 24LC256, fabricados pela Microchip Techenology Inc. As memórias são do tipo EEPROM (Electrically Erasable Programmable Read-Only Memory) e se caracterizam por serem não voláteis e possuírem apagamento por um sinal elétrico. A capacidade do banco de memória é de $128 \mathrm{~kb}$, o que permite armazenar 187 ensaios de penetração no solo, além dos seguintes dados referentes a cada ensaio: número do ensaio; data; latitude e longitude do local do ensaio; tipo de cone escolhido; área da base do cone utilizado; máximo índice 
de cone registrado no ensaio; profundidade onde ocorreu a máxima força; intervalo de profundidade programado para aquisição dos dados no ensaio; força máxima admissível nos ensaios e profundidade programada para o ensaio.

A alimentação e a amplificação do sinal proveniente da célula de carga foram realizadas por meio de um circuito integrado modelo INA 125, fabricado pela Burr-Brown Corp, que incorpora uma fonte de precisão para fornecer tensão de referência e, também, possui um amplificador de instrumentação com ganho programável.

Foi desenvolvido um programa, que se encontra residente no microcontrolador e tem a função de comandar a operação do equipamento e coletar automaticamente os dados. Por meio dele, também é possível introduzir-se, via teclado, as informações necessárias para a identificação de cada ensaio e as condições em que ele deve ser realizado, inclusive a possibilidade de recalibração da célula de carga, caso seja necessário. As condições do ensaio e seu monitoramento são realizados no teclado. Para o funcionamento do microcontrolador, o softwere residente não precisa, obrigatoriamente, estar em linguagem "assembly" específica para tal componente. Foi utilizado um compilador C, marca HITECH Software, tipo ANSI C Compiler, permitindo que grande parte da programação pudesse ser desenvolvida nesta linguagem, simplificando a tarefa de programação. Desenvolveram-se, ainda, sub-rotinas de aquisição de dados, de leitura do teclado, de controle de display, de gravação de dados, de acionamento do motor elétrico e de transferência de dados.

A alimentação de toda a parte eletro-eletrônica do penetrógrafo, é fornecida por duas baterias de $100 \mathrm{Ah}$, que permitem uma autonomia de no mínimo $8 \mathrm{~h}$ de trabalho.

\section{Coleta de dados}

O penetrógrafo é acionado por meio de um botão de partida existente na parte externa da caixa do sistema de controle e aquisição de dados, ou pressionando o botão "enter" do teclado, na função "coletar dados". A aquisição de dados, no entanto, só tem início quando o cone está com sua base rente ao solo (zero de profundidade) graças ao sinal do transdutor capacitivo; a partir daí, os dados são coletados a um intervalo regular de profundidade, podendo este ser ajustado para 2,5, 5, 7,5 ou $10 \mathrm{~mm}$.

A profundidade de penetração do ensaio é programável, podendo ser no máximo de $700 \mathrm{~mm}$. Após atingir a profundidade programada, a haste é recolhida, voltando à posição inicial, estando o penetrógrafo pronto para novo ensaio. $\mathrm{O}$ ensaio é abortado imediatamente se houver uma sobrecarga, ou seja, a força atingir um valor superior à força máxima programada. Nesta situação, o penetrógrafo recolhe a haste à posição inicial e os dados coletados naquele ensaio são descartados.

A qualquer momento ou quando já existem 187 ensaios armazenados no sistema de aquisição, faz-se a transferência dos dados para um microcomputador (PC) por meio de um programa computacional que se instala no PC. Ele copia os dados armazenados na memória do penetrógrafo para um arquivo tipo texto, gravando-o no mesmo diretório em que se encontra instalado; para tanto, o sistema apresenta uma interface de comunicação com PC, via porta de comunicação serial.
O penetrógrafo foi submetido a um ensaio de laboratório, com a finalidade de avaliar a integridade das peças e a velocidade do cone. Aplicaram-se forças de compressão na ponta da haste, sob regime de carga constante, que variaram de zero até $1.226 \mathrm{~N}$, produzindo a resistência à penetração $(\mathrm{RP}) \mathrm{de}$ até $9.474,1 \mathrm{kPa}$ (cone de base de 129,28 $\mathrm{mm}^{2}$ ). Durante os ensaios, a estrutura do penetrógrafo não mostrou nenhum sinal que pudesse comprometer a integridade de suas peças. A Figura 3 apresenta os resultados desse ensaio quanto à velocidade do cone, onde pode ser observada uma variação de no máximo $5 \%$ para a faixa de RP entre zero e $5.684 \mathrm{kPa}$.

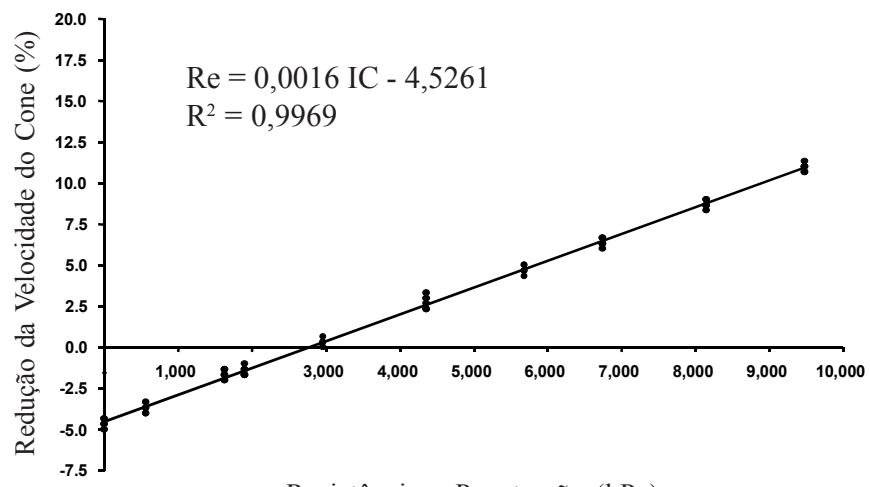

Resistência a Penetração $(\mathrm{kPa})$

Figura 3. Redução da velocidade do cone (\%) em função da resistência a penetração $(\mathrm{kPa})$ calculada para cargas na ponta da haste entre zero a $1.226 \mathrm{~N}$ e cone de $129,28 \mathrm{~mm}^{2}$ de base

A resistência dos solos brasileiros varia, de modo geral, entre 500 a $4.000 \mathrm{kPa}$, como se observa em Fernandez-Medina (1985), Daniel et al. (1994), Bianchini et al. (1996), Klein et al. (1998), Santos \& Lanças (1999) e Tavares Filho et al. (1999) entre outros. Nesta faixa de resistência à penetração, os resultados obtidos pelo penetrógrafo mostraram variação inferior a $5 \%$ na velocidade do cone, que pode ser considerada aceitável, principalmente quando comparado aos penetrógrafos manuais, onde não há controle algum desta velocidade. A própria norma ASAE S313-2 considera que pequenas variações na velocidade do cone não influem nos resultados do IC.

Após a montagem e calibração do sistema de aquisição de dados, o penetrógrafo foi levado a campo, para ensaios. Ele se mostrou prático, de fácil manuseio e alta capacidade operacional realizando, em média, um ensaio a cada minuto. Os dados da força lida, com precisão de $0,5 \mathrm{~N}$, convertidos em índice de cone em $\mathrm{kPa}$, foram armazenados na memória física do sistema de aquisição de dados.

Após os ensaios, os dados foram copiados em um computador, com auxílio do programa de transferência, para que pudessem ser analisados. A Figura 4 mostra, a título de exemplo, um gráfico do comportamento da resistência do solo em função da profundidade, obtido a partir dos dados de um dos ensaios de campo, utilizando-se do cone tipo 1 (área de base de $129,28 \mathrm{~mm}^{2}$ ), intervalo de profundidade para leitura de $2,5 \mathrm{~mm} \mathrm{e}$ profundidade máxima de ensaio de $500 \mathrm{~mm}$. O gráfico mostra claramente as variações de resistência do solo em função da profundidade indicando, inclusive, que há maior resistência na profundidade de $97,5 \mathrm{~mm}$ para o ponto específico onde este ensaio foi executado. 


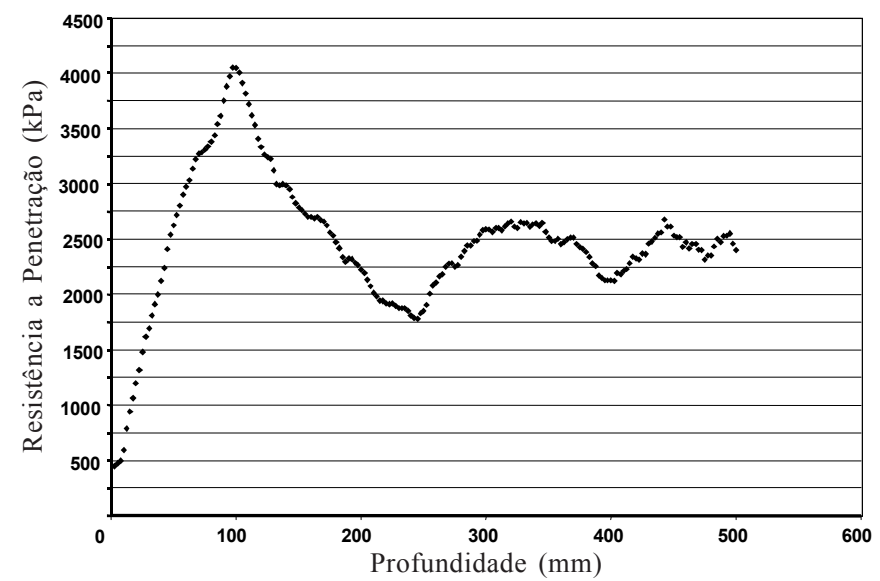

Figura 4. Gráfico obtido pelo penetrógrafo, mostrando o comportamento da resistência do solo à penetração $(\mathrm{kPa})$ em função da profundidade do ensaio $(\mathrm{mm})$

Os dados obtidos em ensaios de campo podem ser manipulados de acordo com a necessidade, para compor gráficos de resistência à penetração, mapas de linhas de isocompactação ou simplesmente subsidiar decisões no que se refere a manejo de solos.

\section{CONCLUSÕES}

O penetrógrafo desenvolvido atendeu aos objetivos propostos, por:

1. Ser um equipamento compacto, de fácil manuseio e alta capacidade operacional (1 ensaio por minuto).

2. Apresentar pequena variação na velocidade de penetração do cone $(\leq 5 \%$, em torno da velocidade padrão) para a faixa de Índice de Cone entre zero e $5.684 \mathrm{kPa}$.

3. Ser totalmente automático e incorporar um sistema dedicado de aquisição de dados.

4. Permitir que se estabeleçam as condições para cada ensaio, via teclado.

\section{LITERATURA CITADA}

ASAE - American Society of Agricultural Engineers S313.2. St. Joseph: Agricultural Engineers Yearbook of Standards, 1998. p.820-1.

Bianchini, A.; Mantovani, E.C.; Martin, P.J. Avaliação de desempenho de um escarificador em solo aluvial. Agricultura Tropical, Cuiabá. v.2, n.1, p.61-72, 1996.

Camargo, O.A.; Alleoni, L.R.F. Compactação do solo e o desenvolvimento das plantas. Piracicaba, 1997. 132p.
Cappelli, N.L.; Daniel, L.A.; Miguel, M.A. Penetrômetro eletrônico para a determinação do índice de cone de solos agrícolas. In: Congresso Brasileiro de Engenharia Agrícola, 24, 1995, Viçosa: SBEA, 1995, 9p. Paper no 95-4-363

Daniel, L.A.; Carvalho, J.F.; Junqueira, G.S. Avaliação de camadas compactadas do solo: efeitos de diferentes sistemas de preparo e cultivo. In: Congresso Brasileiro de Engenharia Agrícola, 23, 1994, Campinas, Campinas: SBEA, Paper nº $94-$ 4-349, n.p.

Fernandez-Medina, B. Influência de dois métodos de preparo de área na compactação de um Latossolo Amarelo. Revista Brasileira de Ciência do Solo, Campinas, v.9, p.67-71, 1985.

Klein, V.A.; Libardi, P.L.; Silva, A.P. Resistência mecânica do solo à penetração sob diferentes condições de densidade e teor de água. Engenharia Agrícola, Jaboticabal, v.18, n.2, p.55-61, 1998.

Lins e Silva, M.L. Modelagem matemática na estimativa da densidade de um Latossolo Vermelho Escuro, textura argilosa, pelo índice de cone. Campinas: UNICAMP, 1999, 161p. Tese Doutorado

Mantovani, E.C.; Queiroz, D.M.; Dias, G.P. Máquinas e operações utilizadas na agricultura de precisão. In: Silva, F.M. (ed.) Mecanização e agricultura de precisão. Poços de Caldas: SBEA, 1998, p.109-157.

Moreira, R.F.; Dias, G.P.; Fontes, L.H.P. Penetrômetro com transdutor tipo anel para medição do índice de cone. In: Congresso Brasileiro de Engenharia Agrícola, 24, 1995, Viçosa: SBEA, 1995, 10p. Paper no 95-4-365

Perumpral, J.V. Cone penetrometer applications - a review. Transaction of the ASAE, St. Joseph, v.30, n.4, p.939-944, 1987.

Santos, C.A.; Lanças, K.P. Projeto e construção de um penetrômetro hidráulico-eletrônico. Energia na Agricultura. Botucatu, v.14, n.4, p.55-61, 1999.

Stein, A.; Staritsky, I.G. Spatanal, Spatin and Optim Software. Wageningen: Wageningen Agricultural University, 1993.

Sudduth, K.A. Engineering and aplication of precision farming technology. In: Hatfield, J.L., Buhler, D. D.; Stewart, B. A. (ed.) Integrated Weed and Soil. London: Ann Arbor Press, 1998, p.311-331.

Tavares Filho, J.; Eira, G.C.; Farinha, L.R.L. Avaliação da compactação em um solo cultivado no sistema convencional. Engenharia Agrícola, Jaboticabal, v.19, n.2, p.219-225, 1999.

Webster, R.; Oliver, M.A. Estatistical methods in soil and land resource survey. Oxford: Oxford University Press, 1990.316p.

Williford, J.R.; Wooten, O.B.; Fulghan, F.E. Tractor mounted field penetrometer. Transaction of the ASAE, St. Joseph, v.15, n.2, p.226-227, 1972. 